\title{
Phytochemical Characterization and Antiplatelet Activity of Mexican Red Wines and Their By-products
}

Ó.A. Muñoz-Bernal ${ }^{1}$, L.A. de la Rosa ${ }^{1}$, J. Rodrigo-García ${ }^{2}$, N.R. Martínez-Ruiz ${ }^{1}$, S. Sáyago-Ayerdi ${ }^{3}$ L. Rodriguez ${ }^{4}$, E. Fuentes ${ }^{4}$, I. Palomo ${ }^{4}$, E. Alvarez-Parrilla ${ }^{1 *}$

Universidad Autónoma de Ciudad Juárez, Ciudad Juárez. Instituto de Ciencias Biomédicas

(1) Departamento de Ciencias Químico-Biológicas

(2) Departamento de Ciencias de la Salud, Ciudad Juárez, Chihuahua, México

(3) Tecnológico Nacional de México/Instituto Tecnológico de Tepic, Av. Tecnológico No 2595, Col. Lagos del Country, CP 63175, Tepic, Nayarit, México

(4) Thrombosis Research Center, Department of Clinical Biochemistry and Immunohaematology, Faculty of Health Sciences, Chile State Universities Network on Aging. Universidad de Talca, Talca, Chile

Submitted for publication: December 2020

Accepted for publication: March 2021

Keywords: condensed tannins, grape pomace, phenolic profile, platelet aggregation, red wine

Red wines and their grape pomaces are important sources of phenolic compounds. Inhibition of platelet aggregation is one of the mechanisms proposed for cardioprotective effect of phenolic compounds from wine and grape pomace; however, phenolic content is affected by region, variety and winemaking process. In the present study, antiplatelet effect of red wines and grape pomaces was related to its phenolic content (determined by spectrophotometric techniques) and profile (determined using HPLC-MS/MS). in vitro Anti-platelet aggregation was determined using human platelets. Results showed that Zinfandel wine and Cabernet Sauvignon grape pomace presented the highest phenolic content. Phenolic profiles presented differences in the presence of flavonoids and oligomeric tannins. Results from platelet aggregation showed that Merlot and Petit Verdot wines and Petit Verdot grape pomace sample presented the highest antiaggregant effect. These results indicate that antiplatelet effect could be related to phenolic profile than phenolic content in wines and grape pomaces. Cardioprotective effect of red wines and grape pomace could be related to specific compounds such as monomeric and polymeric flavan-3-ols.

\section{INTRODUCTION}

Phenolic compounds play an important role in oenology since they are related with organoleptic characteristics of wine such as colour, aroma, astringency and bitterness (Burin et al., 2011). Final phenolic content and phenolic profile of wines depends on (but are not limited to) viticulture processes and environmental conditions associated with the grape growing region. Therefore, phenolic compounds have been used to determine wine quality, authenticity of geographical origin, varietal differentiation and clone differentiation (Burin et al., 2011; Figueiredo-González et al., 2012). Anthocyanins and flavonols are the principal fractions of phenolic compounds used for such assessments. Although, anthocyanin and flavonol content depends on several factors, and specific anthocyanin profile depends cultivar, and is related to the cultivar's genetic information (Figueiredo-González et al., 2012).

During winemaking, large amounts of grape pomace are generated. This is the main by-product of the wine industry and its waste treatment is expensive (Tournour et al., 2015).
Since not all the phenolic compounds present in grapes are transferred into wine during the maceration-fermentation process, grape pomace is considered an important source of phenolic compounds (Beres et al., 2017). Studies have proposed the use of this by-product to obtain phenolic compounds due to their antioxidant attributes (Lingua et al., 2016), antimicrobial (Oliveira et al., 2013), anticancer and anti-inflammation activity properties among others (Denny et al., 2014).

In the last few years, the Mexican winemaking industry has shown a steady growth pattern, mainly due to increasing internal consumption and exportation (Font et al., 2010). For this reason, generation of grape pomace has increased, and it is necessary to evaluate its phenolic composition to promote the use of this by-product.

Moreover, consumption of phenolic compounds present in red wines and grape pomaces is associated with low prevalence of cardiovascular diseases, even though the mechanism of prevention is not well established yet (Muñoz-

*Corresponding author: ealvarez@uacj.mx

Acknowledgements: Authors thank Grupo Alximia S.A. de C.V. for all facilities and donated samples. OAMB thanks CONACYT for his PhD scholarship. Financial support from CYTED (Red Iberoamericana de Aprovechamiento Integral de Alimentos Autóctonos Subutilizados, ALSUB-CYTED-118RT0543). 
Bernal et al., 2021). It has been proposed that phenolic compounds present in red wines can improve endotheliumdependent vasodilation, increase antioxidants in plasma and inhibit platelet aggregation (Gresele et al., 2008).

Platelet aggregation is associated with the development of the atherosclerotic process and the prevention of this phenomenon has been accepted as a cardio-protection mechanism of phenolic compounds present in red wine and other grape products (Faggio et al., 2017; Lutz et al., 2019; Muñoz-Bernal et al., 2021). Previous studies of antiplatelet effects of wines have shown controversial results. Ex vivo studies after the intake $250 \mathrm{~mL}$ of red wine from Montepulciano d'Abruzzo during 4 weeks demonstrated no significant effect against platelet aggregation (Giuliana et al., 2011). In vitro assays compared the effect of red wine from Rioja, a commercial extract of phenolic compounds and ethanol against platelet aggregation, observing no effect for the alcohol and a dose-dependent effect pattern for the wine and the phenolic extract (de Lange et al., 2003). Other authors have reported inhibition of platelet aggregation in hypercholesterolemic rabbits after the ingestion of red wine (Wang et al., 2002). Bioactivity of phenolic compounds depends on their bioavailability and bioaccessibility and how they can tolerate the different conditions during the gastrointestinal digestion (Lingua et al., 2019). This process is determinant to observe the beneficial effect on health of phenolic compounds from red wines. However, in vitro antiplatelet aggregation studies have been extensively used to evaluate the protective effect of foods and extracts (Muñoz-Bernal et al., 2021).

This antiplatelet activity has not been associated to the phenolic profile of wines and grape pomaces. Moreover, phenolic content of red wines and grape pomaces depends on climate and geographic area of growth, as well as grape genetic information. There is little information about the phenolic content and profile of red wines and grape pomaces from Baja California, Mexico region (Muñoz-Bernal et al., 2020).

The aim of the present study was to determine the phenolic content and phenolic profile of nine Mexican red wines and grape pomaces and evaluate their antiplatelet aggregation using human platelets. It was hypothesized that, the phenolic profile from the nine wines and grape pomace samples, and not their phenolic content, regulates their antiplatelet aggregation.

\section{MATERIALS AND METHODS \\ Chemicals}

Folin-Ciocalteu reagent, adenosine diphosphate (ADP), thrombin receptor activating peptide 6 (TRAP-6), sodium citrate $3.2 \%$, phosphate buffer solution (PBS), sodium carbonate, sodium nitrate, aluminum chloride, sodium hydroxide, sodium acetate, vanillin, p-dimethylaminocinnamaldehyde (DMAC), catechin and gallic acid were purchased from Sigma-Aldrich (St. Louis, MO, USA). Gallic acid, catechin, epicatechin, ellagic acid, protocatechuic acid, vanillin, chlorogenic acid were HPLC grade standards and purchased from Sigma-Aldrich (St. Louis, MO, USA). HPLC grade acetonitrile was purchased from Tedia (Fairfield, OH, USA). HPLC grade formic acid was purchased from Sigma-Aldrich (St. Louis, MO, USA). All other reagents were analytical grade.

\section{Wine and grape pomace samples}

Wine and grape pomace from nine different varietals were kindly donated by Grupo Alximia S.A. de C.V. from "Valle de Guadalupe", Baja California, Mexico (latitude 32 ${ }^{\circ} 7^{\prime}$ $25.1^{\prime \prime}$ north, longitude $116^{\circ} 32^{\prime} 23.9^{\prime \prime}$ west, 378 masl), during the 2017 vintage. Grape varieties from Vitis vinifera L. $\mathrm{cv}$. used in this study were Barbera (BA), Carignan (CA), Cabernet Sauvignon(CS), Grenache (GR), Merlot(ME), Petit Verdot (PV), Syrah (SY), Tempranillo (TE) and Zinfandel (ZI). Grapes at grape mature $\left(22-25^{\circ}\right.$ Brix and $\mathrm{pH}$ below 3.4) were harvested by hand and transported to the winery in plastic baskets. Immediately, grapes were destemmed and crushed and placed in stainless tanks with capacity of 4 tonnes, then $120 \mathrm{mg} / \mathrm{L}$ of $\mathrm{SO}_{2}$ were added. Maceration process was carried out at $10^{\circ} \mathrm{C}$ for 5 days. For fermentation, Saccharomyces cerevisiae was added to initiate fermentation (500 $\mathrm{g}$ for $4 \mathrm{hL}$ ). Yeast used were Barolo (Scott Labs, BRL97) for BA and ZI, Lalvin (Scott Labs, CLOS) for CS, ICV (Scott Labs, GRE), Rhône (Scott Labs, 2056), Enoferm (Scott Labs, Syrah) for SY, Lalvin (Scott Labs, T73) for TE, Lalvin (Scott Labs, BM45) for CA and Fermivin (Scott Labs, MT48) for ME. Fermentation was controlled at $23{ }^{\circ} \mathrm{C}$, without removal of grape pomace, density was measured with hydrometer to monitor maceration-fermentation process. Tanks were pumped over for 30-45 min, 3 times/day, during all the process. Just before sample collection, wines were pumped over to assess sample homogeneity. Grape pomace and monovarietal young red wine samples were taken from the total production of the winery. Three independent wine samples from each variety were taken after the fermentation process was complete $(250 \mathrm{~mL}$ each), just before the wine was transferred to the barrels. Grape pomace samples were taken just after the press process, three independent samples were taken (1 kg each). Samples of grape pomace and wine were vacuum stored at $-20^{\circ} \mathrm{C}$ and transported to laboratory at Ciudad Juárez, Chihuahua, México. Wine and grape pomace samples were kept at $-80^{\circ} \mathrm{C}$ (Thermo Scientific ${ }^{\circledR}$, 8924EXF32086D) until further analysis.

\section{Extraction of phenolic compounds from grape pomace} Grape pomace samples were dried at $55^{\circ} \mathrm{C}$ for $48 \mathrm{~h}$ in a convection oven (Fisher Scientific ${ }^{\circledR}$, Isotemp oven). According to Goula et al. (2016), drying temperatures from $60-85^{\circ} \mathrm{C}$, produces a loss of phenolic compound, from this basis $55^{\circ} \mathrm{C}$ was selected to dry grape pomace samples. Once dried, samples were grinded and sieved $(450 \mu \mathrm{m}$ pore size). Dried grape pomaces samples (10 g) were extracted with acidified methanol $80 \%(1 \% \mathrm{HCl}$ in water $)$ at a $1: 25$ (solid: solvent) ratio. Acidified methanol was used to obtain soluble or extractable phenolic compounds of low molecular weight, such as phenolic acids and anthocyanins. $\mathrm{HCl}$ was used to maintain a low $\mathrm{pH}$ and prevent hydrolysis reactions (Goula et al., 2016; Domínguez-Rodríguez et al., 2017). Samples were sonicated (Branson $\left.{ }^{\circledR}, 5800\right)$ during $30 \mathrm{~min}$ and centrifugated (Eppendorf $\left.{ }^{\mathbb{}}, 5810 \mathrm{R}\right)$ at $2465 \mathrm{~g}$ for $15 \mathrm{~min}$ at $4^{\circ} \mathrm{C}$. The supernatant was collected, and the 
pellet was extracted once again under the same conditions. Both supernatants were mixed and stored at $-20^{\circ} \mathrm{C}$. The pellet from the methanolic extraction was extracted using acetone $70 \%$ in a 1:25 (solid: solvent) ratio, following the previous described extraction procedure. Acetone 70\% was also used to obtain high molecular weight extractable phenolic compounds, such as oligomeric flavan-3-ols (Goula et al., 2016). Methanol and acetone from supernatants were separately distilled using a rotavapor (Büchi $\left.{ }^{\circledR}, \mathrm{R}-3\right)$ at $50^{\circ} \mathrm{C}$. The aqueous parts were mixed, frozen at $-80^{\circ} \mathrm{C}$ overnight and lyophilized (Labconco ${ }^{\circledR}$, Freezone 6) for 48 h. Finally, the extract was vacuum stored at $-80^{\circ} \mathrm{C}$. This sample represented the soluble phenolic extract (SPE). The pellet obtained after the acetone extraction was oven dried (Fisher Scientific ${ }^{\circledR}$, Isotemp oven) at $50^{\circ} \mathrm{C}$ for $24 \mathrm{~h}$. After this period, a basic hydrolysis was performed. Basic hydrolysis was performed to obtain the non-extractable phenolic compounds. Nonextractable phenolic are bounded with polysaccharides and proteins through ester bounds. Basic hydrolysis breaks these ester bonds from polysaccharides, hydrolyses cell walls and solubilize proteins (Beres et al., 2017; DomínguezRodríguez et al., 2017). Basic hydrolysis was performed according to method described by Cheng et al. (2014), with modifications. Grape pomace pellet $(5 \mathrm{~g})$ was poured in a boiling flask, then $3 \mathrm{M}$ sodium hydroxide was added at a 1:10 (solid:solvent) ratio. The mix was refluxed for $4 \mathrm{~h}$ at $80^{\circ} \mathrm{C}$ (water bath) with constant agitation. Once hydrolysis was finished, $\mathrm{pH}$ was adjusted to 2 with concentrated $\mathrm{HCl}$ $(37 \%)$ and centrifugated at $2465 \mathrm{~g}$ for $15 \mathrm{~min}$ at $4^{\circ} \mathrm{C}$. The supernatant was adjusted to $50 \mathrm{~mL}$ with distilled water and stored at $-20^{\circ} \mathrm{C}$ until further analysis (bound phenolic extract, BPE). For spectrophotometric determinations, SPE extracts were dissolved in methanol $(1 \mathrm{mg} / \mathrm{mL})$, while BPE and wine samples were analysed directly.

\section{Total phenolic compounds}

Total soluble phenolic compounds (TSP) present in wine and total phenolic content (TPC) in grape pomace were measured by the Folin-Ciocalteu method as described previously (Muñoz-Bernal et al., 2020). The Folin-Ciocalteu reagent is a mixture of phosphomolybdic and phosphotungstic acids, the molybdenum ions interacts with hydroxyl groups of phenolic compounds to produce a blue complex and absorbance is measured at $765 \mathrm{~nm}$ (Muñoz-Bernal et al., 2017). In a 96well plate, $25 \mu \mathrm{L}$ of standard or sample were poured, and mixed with $100 \mu \mathrm{L}$ of sodium carbonate $(7.5 \% \mathrm{w}: \mathrm{v})$. Then, $125 \mu \mathrm{L}$ of Folin-Ciocalteu reagent (10\% in distilled water) were added. Well plate reader $\left(x M a r k, B i o R A D^{\circledR}\right)$ was set at $765 \mathrm{~nm}$ and $45^{\circ} \mathrm{C}$, and programmed to shake $5 \mathrm{~s}$ and read the well at $1 \mathrm{~min}$ interval for $15 \mathrm{~min}$. Gallic acid was used as standard, and results were expressed as milligrams of gallic acid equivalents per liter (mg GAE/ L) for wine and per gram of dried matter (g DM) for grape pomace.

\section{Total flavonoid content}

Total soluble flavonoids (TSF) were determined in wine and total flavonoid content (TFC) were determined in grape pomace by the aluminum chloride complexation method (Muñoz-Bernal et al., 2020). In this method, aluminum ions $\left(\mathrm{Al}^{3+}\right)$ interacts with the hydroxyl groups in the catecholic moiety of ring B of flavonoids (Granato et al., 2016), the complex absorbance is measured at $510 \mathrm{~nm}$. In a 96-well plate, $31 \mu \mathrm{L}$ of standard or sample were diluted with $125 \mu \mathrm{L}$ of distilled water. Then, $9.5 \mu \mathrm{L}$ of sodium nitrite $(5 \% \mathrm{w}: \mathrm{v})$ and $9.5 \mu \mathrm{L}$ of aluminum chloride $(10 \% \mathrm{w}: \mathrm{v})$ were added. Finally, $125 \mu \mathrm{L}$ of sodium hydroxide were poured. Reaction was incubated for $30 \mathrm{~min}$ at room temperature. Reaction was measured at $510 \mathrm{~nm}$ in a well plate reader. Catechin was used as standard, and results were expressed as milligrams of catechin equivalents per liter (mg CE/L) for wine and per gram of dried matter (g DM) for grape pomace.

\section{Condensed tannin content}

Quantification of total soluble condensed tannins (TST) in wine samples and total condensed tannin content (TTC) in grape pomace samples was performed according to the p-dimethylaminocinnamaldehyde DMAC method (MuñozBernal et al., 2020). DMAC method has been described as a specific method for the quantitation of condensed tannins in food matrices, the DMAC undergoes to a condensation reaction with hydroxyl groups in ring A of flavan-3-ols, reaction absorbance is measured at $640 \mathrm{~nm}$ (Payne et al., 2010). In a 96-well plate, $50 \mu \mathrm{L}$ of standard or sample were mixed with $250 \mu \mathrm{L}$ of DMAC reagent $(0.1 \%$ (w:v) in acidified methanol (10\% v:v)). Mixture was incubated for $10 \mathrm{~min}$ at room temperature and light absence. Reaction was measured in a well plate reader at $640 \mathrm{~nm}$. Catechin was used as standard, and results were expressed as milligrams of catechin equivalents per liter ( $\mathrm{mg} \mathrm{CE} / \mathrm{L})$ for wine and per gram of dried matter ( $\mathrm{g} D \mathrm{DM})$ for grape pomace.

\section{Anthocyanin content}

Total soluble anthocyanins (TSA) in wine samples and total anthocyanin content (TA) content in grape pomace samples (SPE, BPE, and wine) was determined by $\mathrm{pH}$ shift (Lee et al., 2005) with modifications (Muñoz-Bernal et al., 2020). The $\mathrm{pH}$ shift method to quantify monomeric anthocyanins is based in the reversible structural change that anthocyanins undergo at different $\mathrm{pH}$. At $\mathrm{pH} 1$ a coloured oxonium formed, meanwhile at $\mathrm{pH} 4.5$ a hemiketal form is present, such form is colourless (Lee et al., 2005). In a test tube, $250 \mu \mathrm{L}$ of sample were mixed with $2 \mathrm{~mL}$ of potassium chloride $(2 \mathrm{M}, \mathrm{pH} 1)$. Mixture was incubated for $20 \mathrm{~min}$ at room temperature. In another test tube, $250 \mu \mathrm{L}$ of sample were mixed with $2 \mathrm{~mL}$ of sodium acetate (2 M, pH 4.5). Mixture was incubated for $20 \mathrm{~min}$ at room temperature. After incubation period, $300 \mu \mathrm{L}$ of each tube were placed in a 96-well plate. Absorbance was read at $520 \mathrm{~nm}$ and $700 \mathrm{~nm}$. Anthocyanin content in samples was calculated using Equation 1.

$\frac{m g M 3 G}{L}=\frac{A \times M W \times D \cdot F \times 10^{3}}{\varepsilon \times 1}$

Equation 1

Where: $A=\left(\mathrm{Abs}_{520}-\mathrm{Abs}_{700}\right)_{\mathrm{pH} 1}-\left(\mathrm{Abs}_{520}-\mathrm{Abs}_{700}\right)_{\mathrm{pH} 4.5}, M W$ (molecular weight $)=493.4 \mathrm{~g} \mathrm{~mol}^{-1}$ for malvidin 3-glucoside, $D . F .=$ dilution factor used $(1: 5), 10^{3}=$ factor conversion $\mathrm{g}$ to $\mathrm{mg}, \varepsilon=28,000$ molar extinction coefficient in $\mathrm{L} / \mathrm{mol} \mathrm{cm}, 1=$ path length in $\mathrm{cm}$. Results were expressed as milligrams of malvidin-3-glucoside equivalents per liter (mg M3G/L) for wine and per gram of dried matter (g DM) for grape pomace. 
Phenolic profile of wines and grape pomaces by HPLCESI-MS/MS

An Agilent Infinity Series 1290 LC system combined with an Agilent 6500 Series Q-TOF MS (Agilent ${ }^{\circledR}$ Technologies, Santa Clara, CA, USA) system was used in this study. The Agilent Mass Hunter Software MS (Agilent ${ }^{\circledR}$ Technologies, Santa Clara, CA, USA) was applied on the system. The HPLC system consisted of a 1290 Infinity quaternary pump with built-in degasser, 1290 Infinity autosampler with temperature control, 1290 Infinity thermostated column compartment, and 1290 Infinity diode-array detector. A Zorbax Eclipse plus $\mathrm{C}_{18}$ column $(50 \mathrm{~mm} \times 2.1 \mathrm{~mm}, 1.8 \mu \mathrm{m})$ (Agilent ${ }^{\circledR}$ Technologies, Santa Clara, CA, USA), was used at $25{ }^{\circ} \mathrm{C}$ for the separations. The flow rate of the mobile phase was $0.4 \mathrm{~mL} / \mathrm{min}$. A multi-step gradient method was applied, using $0.1 \%(\mathrm{v} / \mathrm{v})$ formic acid in water as solvent $\mathrm{A}$ and pure acetonitrile as solvent B. For the elution program, the following proportion of solvent $\mathrm{B}$ was used: $0-1 \mathrm{~min}$ $10 \%, 1-4 \min 30 \%$, 4-6 min $38 \%$, 6-8 $\min 60 \%, 8-8.5$ $\min 60 \%, 8.5-9 \min 10 \%$, according to method described by Torres-Aguirre et al. (2018). The injection volume was $1 \mu \mathrm{L}$. Samples were filtered through $0.45 \mu \mathrm{m}$ nylon filters and injected into the HPLC-DAD-MS system. Wine and BPE samples were injected directly. SPE was injected at $1 \mathrm{mg} / \mathrm{mL}$. The mass spectrometer Agilent 6530Accurate Mass Q-TOF LC-MS was equipped with an electrospray ion source (ESI), operated in negative mode. Nitrogen was used as drying gas at $340^{\circ} \mathrm{C}$, with a flow rate of $13 \mathrm{~L} / \mathrm{min}$; pressure of the nebulizer was set at $60 \mathrm{psi}$ (4.22 atm), capillary voltage $175 \mathrm{~V}$ and the scanning mass to charge range of the Q-TOF mass analyzer was $100-3200 \mathrm{~m} / z$. For MS/MS scanning was from $100-1000 \mathrm{~m} / \mathrm{z}$

The identification of phenolic compounds was performed using retention times, UV/Vis spectra, and mass spectra from qTOF-MS using the Mass Hunter Qualitative software version B.07.00. For identification of compounds, Molecular Feature extraction (MFE) tool was used to identified coeluted compounds and Generate Formula (GF) tool was used to obtain isotopic distribution and high-resolution exact mass of compounds identified. With retention times, isotopic distribution, exact mass (with a difference of $5 \mathrm{ppm}$ in contrast with theorical mass) and fragments obtained from MS/MS, compounds of interest were compared to Metlin data base included in the Mass Hunter PCDL Manager for Metabolomics B.07.00 and wine phenolic compounds previously reported in literature. Ions were identified when their abundance was between 100 and 20000 counts, ions bellow those abundances, signals were taken as noise. The score of matches used to identify compounds was $>75 \%$, lower scores were taken as unidentified compounds.

\section{Antiplatelet activity of wine and grape pomace}

The antiplatelet activity was evaluated as antiaggregation effect on human platelets (Fuentes et al., 2018). Briefly, blood samples were obtained from 6 healthy volunteers, who previously signed the informed consent and did not consume antiplatelet non-steroidal anti-inflammatory drugs (NSAIDs) or other medications. To obtain platelet-rich plasma (PRP) blood was centrifugated at 2040 g (DCS-16 Centrifugal Presvac RV), then the platelets were adjusted using platelet poor plasma (PPP) to $200 \times 10^{9}$ platelets/L using a hematologic counter (Bayer Advia 60 Hematologic System). Samples of wine and SPE were lyophilized and suspended in a phosphate buffer solution (PBS). To measure the antiplatelet effect of samples, a lumi-aggregometer (Chrono-log, Havertown) was used. SPE and wine samples were added at $1 \mathrm{mg} / \mathrm{mL}$ final concentration to adjusted PRP (200 x $10^{9}$ platelets/L)(Born \& Cross, 1963). Adjusted PRP was incubated with PBS (negative control, maximum platelet aggregation) or with samples of wine and SPE at $37^{\circ} \mathrm{C}$ for 3 min in constant agitation before adding the agonist, while the antiplatelet agent adenosine $(10 \mu \mathrm{M})$ was used as a positive control. Agonists used were ADP $(4 \mu \mathrm{M})$ and TRAP-6 $(10 \mu \mathrm{M})$ and the effect of wine and extracts against platelet aggregation was monitored for 6 min and compared to a PBS buffer. Platelet aggregation was measured as the increase in light transmission over 6 minutes and results were expressed as percentage aggregation with AGGRO/LINK software (Chrono-Log, Havertown, PA, USA) (Sepúlveda et al., 2019). The inhibition of platelet aggregation was calculated using Equation 2.

$\%$ Inhibition $=100-\frac{(\% \text { Paltelet aggregation of samples }) \mathrm{x}(100)}{\% \text { Platelet aggregation negaive control }}$

Equation 2

\section{Statistical analysis}

Each analysis was performed in triplicate (technical repeats), using three replicates (biological repeats). Results express average and standard error of mean (SEM). One-way analysis of variance (ANOVA) was applied and Tukey's posthoc test was used for comparison of mean value. Principal component analysis (PCA) was applied to evaluate the phenolic profile and the variety of each wine sample. Hierarchical cluster analysis (HCA) was performed to evaluate dissimilarity between wine and grape pomace samples. All the analyses were performed using XLSTAT software (Addinsoft, Boston, MA, USA). Level of significance used for analyses was $\mathrm{p} \leq 0.05$. Anti-platelet aggregation data were analysed using Prism 8.0 software (GraphPad Inc., San Diego CA, USA) and expressed as mean \pm standard error (SEM). Differences between groups were analysed using ANOVA and Tukey's post hoc test.

\section{RESULTS AND DISCUSSION}

Quantification of total phenolic compounds in wine and grape pomace by spectrophotometric techniques

Final phenolic content in red wines depends on several parameters like environmental factors, grape ripeness, grape variety, vintage and winemaking process (Lingua et al., 2016). In the present study, the differences observed in the 9 wines, could be attributed mainly to grape variety, since the ripeness (determined by sugar content and acidity of grapes), vintage season and the winemaking process were the same for all wines. Results of total soluble phenols (TSP) are shown in Table 1. ZI wine showed the highest content $(3454 \mathrm{mg}$ GAE/L). Wines from CS, PV and TE wines presented values from 2700 to $2900 \mathrm{mg}$ GAE/L and were statistically similar. Meanwhile, CA wine presented the lowest TSP (1749 mg GAE/L). Jiang \& Zhang (2012), compared the TSP values 
from CS and ME wine and reported that CS wines had a higher value of TSP than ME wine this is in accordance with result observed in the present study.

Flavonoids were the most abundant fraction present in red wines compared to tannins and anthocyanins, similar behavior have been previously reported (Jiang \& Zhang, 2012). Quantification of total soluble flavonoids (TSF) in wines are shown in Table 1. ZI presented the highest TSF (955 mg CE/L). TSF found in ZI wine was lower compared with those previously reported in the literature $(1931 \mathrm{mg}$ CE/L) (Coletta et al., 2014). SY and ME wines presented the lowest TSF (390 and $412 \mathrm{mg} \mathrm{CE} / \mathrm{L}$ respectively). Previously it has been reported that $\mathrm{ME}$ wines presented lower content of flavonoids than CS wines (Jiang \& Zhang 2012), this is in accordance with results observed in the present study.

Total soluble tannins (TST) quantified in wines are summarized in Table 1. ZI, CS and PV presented similar TST and, showed the highest values compared to the other varieties of wine (514, 463 and $536 \mathrm{mg} \mathrm{CE} / \mathrm{L}$, respectively). These results were in concordance with those observed in the TSP and TSF, where these varieties of wine presented the highest values. The wine with the lowest TST was SY (113 mg $\mathrm{CE} / \mathrm{L})$. Previous studies have reported higher TST content for CS (1125 mg CE/L) and ME (619 mg CE/L) wines (Panceri et al., 2015). The low tannin content found in the present study (almost half of the reported values) could be attributed to differences in the spectrophotometric methods employed to determine the content of this type of phenolic compounds. The principal methods used to quantify condensed tannins in wines are based on reactivity of the phenolic rings (Preys et al., 2006), depolymerization techniques (Ghanem et al., 2017) and precipitation of tannins (Balea et al., 2018). In the present study DMAC was used to quantify TST, because this method is more specific than other commonly used methods such as vanillin in methanol method (Schofield et al., 2001), since DMAC reacts only with terminal units of condensed tannins, while other methods could overestimate condensed tannin content (Versari et al., 2013; Muñoz-Bernal et al.,
2020).

Total soluble anthocyanin content (TSA) values for each wine variety are shown in Table 1 . Results showed a different trend compared to those observed for TSP and TSF. PV wine showed the highest TSA (201 mg C3G/L). ZI wine presented the highest TSP and TSF values, however its TSA was lower. CA wine presented the lowest TSA (76 mg C3G/L). Differences on TSA content can be attributed to formation of pyranoanthocyanins, degradation and condensation reactions with other phenolic compounds (Casassa \& Harbertson 2014). Jin et al. (2009), reported that grapes from CS, SY and ME have similar anthocyanin content and were higher compared to grapes from ZI. These results is similar than those found in the present study where ZI wine have low TSA values. In recent years, it is commonly accepted that anthocyanin profile in grapes and wines is strongly related to their genetic information. Nevertheless, TSA values may vary according to season conditions(Ortega-Regules et al., 2006).

Results of total phenolic content (TPC, SPE and BPE) in the nine varieties of grape pomace are shown in Table 2. These results were obtained from the quantifications made from methanol, acetone and basic hydrolysis extracts. Grape pomace from CS presented the highest TPC (131.65 mg GAE/g DM). Grape pomace from GR, ME and PV showed similar TP. In contrast with the results obtained for ZI wine, its grape pomace showed low TPC content. Grape pomace from SY exhibited the lowest TPC (93 mg GAE/g DM). In another study, TPC from SY, ME and CS grape pomaces were evaluated, through a methanolic extraction, reporting extremely low values ( 0.98 to $2.12 \mathrm{mg} \mathrm{GAE} / \mathrm{g} \mathrm{DM}$ ) (Lingua et al., 2016). Other authors reported for TE grape pomace, using methanol and acetone extracts, TPC values of $48.4 \mathrm{mg}$ GAE/g DM (Wang et al., 2017). Comparing with these results, it is possible to observe that extraction conditions and methods regulate the amount of phenolic compounds extracted from grape pomace. Ultrasound assisted extraction of phenolic compounds from grape pomace have presented

TABLE 1

Spectrophotometric analysis of wines for quantification of total phenolic compounds and their fractions.

\begin{tabular}{llccc}
\hline Wine & \multicolumn{1}{c}{ TSP } & TSF & TST & TSA \\
\hline BA & $2311 \pm 81.71^{\mathrm{cd}}$ & $711.6 \pm 58.71^{\mathrm{bc}}$ & $240.8 \pm 7.35^{\mathrm{c}}$ & $151.91 \pm 5.71^{\mathrm{d}}$ \\
CA & $1749 \pm 36.04^{\mathrm{e}}$ & $629.3 \pm 62.57^{\mathrm{c}}$ & $149.6 \pm 17.34^{\mathrm{de}}$ & $80.56 \pm 1.50^{\mathrm{h}}$ \\
GR & $2452 \pm 117.80^{\mathrm{c}}$ & $626.8 \pm 27.22^{\mathrm{c}}$ & $321.7 \pm 42.45^{\mathrm{b}}$ & $125.67 \pm 0.75^{\mathrm{g}}$ \\
CS & $2739 \pm 32.28^{\mathrm{b}}$ & $729.4 \pm 58.32^{\mathrm{bc}}$ & $462.2 \pm 21.56^{\mathrm{a}}$ & $193.43 \pm 3.75^{\mathrm{c}}$ \\
ME & $2114 \pm 73.97^{\mathrm{d}}$ & $390.1 \pm 10.29^{\mathrm{d}}$ & $218.5 \pm 11.28^{\mathrm{cd}}$ & $149.10 \pm 1.67^{\mathrm{de}}$ \\
PV & $2810 \pm 37.26^{\mathrm{b}}$ & $772.7 \pm 5.09^{\mathrm{b}}$ & $536.2 \pm 48.96^{\mathrm{a}}$ & $213.08 \pm 1.10^{\mathrm{a}}$ \\
SY & $2281 \pm 112.90^{\mathrm{cd}}$ & $412.1 \pm 70.64^{\mathrm{d}}$ & $113.8 \pm 18.41^{\mathrm{e}}$ & $139.26 \pm 0.78^{\mathrm{f}}$ \\
TE & $2936 \pm 58.42^{\mathrm{b}}$ & $670.1 \pm 36.38^{\mathrm{bc}}$ & $352.5 \pm 33.76^{\mathrm{b}}$ & $201.81 \pm 1.53^{\mathrm{b}}$ \\
ZI & $3454 \pm 87.63^{\mathrm{a}}$ & $956.0 \pm 36.70^{\mathrm{a}}$ & $514.7 \pm 22.29^{\mathrm{a}}$ & $143.43 \pm 1.27^{\mathrm{ef}}$ \\
\hline
\end{tabular}

Results express the Mean of three replicates. $( \pm)$ standard deviation of the mean. Different letter express difference between the different grape varieties at $p<0.05$ (Tukey test). TSP are expressed as milligrams of gallic acid equivalents per litter. TSF are expressed as milligrams equivalents of catechin per litter. TST are expressed as milligrams equivalents of catechin per litter. TSA are expressed as milligrams equivalents of malvidin-3-glucoside per litter. 
TABLE 2

Spectrophotometric results of grape pomace.

\begin{tabular}{lcccc}
\hline Grape pomace & TPC & TFC & TTC & TAC \\
\hline BA & $102.7 \pm 3.58^{\mathrm{cd}}$ & $56.24 \pm 5.91^{\mathrm{bc}}$ & $7.23 \pm 1.07^{\mathrm{e}}$ & $1.49 \pm 0.08^{\mathrm{a}}$ \\
CA & $109.6 \pm 7.89^{\mathrm{bc}}$ & $77.45 \pm 5.71^{\mathrm{ab}}$ & $10.27 \pm 0.31^{\mathrm{de}}$ & $1.64 \pm 0.18^{\mathrm{a}}$ \\
GR & $118.3 \pm 8.09^{\mathrm{ab}}$ & $74.12 \pm 2.65^{\mathrm{abc}}$ & $13.24 \pm 0.65^{\mathrm{cd}}$ & $0.82 \pm .05^{\mathrm{b}}$ \\
CS & $131.7 \pm 6.20^{\mathrm{a}}$ & $86.47 \pm 9.74^{\mathrm{a}}$ & $20.54 \pm 3.50^{\mathrm{ab}}$ & $0.51 \pm .05^{\mathrm{b}}$ \\
ME & $119.9 \pm 2.45^{\mathrm{ab}}$ & $71.70 \pm 10.08^{\mathrm{abc}}$ & $17.01 \pm 0.26^{\mathrm{bc}}$ & $1.58 \pm 0.11^{\mathrm{a}}$ \\
PV & $123.6 \pm 9.80^{\mathrm{ab}}$ & $73.39 \pm 4.41^{\mathrm{abc}}$ & $23.48 \pm 2.91^{\mathrm{a}}$ & $1.44 \pm 0.09^{\mathrm{a}}$ \\
SY & $93.94 \pm 3.19^{\mathrm{d}}$ & $53.22 \pm 3.97^{\mathrm{c}}$ & $10.05 \pm 1.90^{\mathrm{de}}$ & $1.55 \pm 0.21^{\mathrm{a}}$ \\
TE & $111.6 \pm 4.21 \mathrm{~b}^{\mathrm{c}}$ & $68.62 \pm 9.78^{\mathrm{abc}}$ & $9.98 \pm 1.32^{\mathrm{de}}$ & $1.50 \pm 0.24^{\mathrm{a}}$ \\
ZI & $101.1 \pm 2.86^{\mathrm{cd}}$ & $72.00 \pm 9.95^{\mathrm{abc}}$ & $9.54 \pm 0.80^{\mathrm{de}}$ & $1.72 \pm 0.04^{\mathrm{a}}$ \\
\hline
\end{tabular}

Results express the Mean of three replicates. $( \pm)$ standard deviation of the mean. Different letter express difference between the different grape varieties at $\mathrm{p}<0.05$ (Tukey test). TPC are expressed as milligrams of gallic acid equivalents per gram of dry matter. TFC are expressed as milligrams equivalents of catechin per gram of dry matter. TTC are expressed as milligrams equivalents of catechin per gram of dry matter. TAC are expressed as milligrams equivalents of malvidin-3-glucoside per gram of dry matter.

better results compared to Soxhlet and super fluid extraction (Oliveira et al., 2013). On the other hand, phenolic extraction from grape pomace using acidified methanol has demonstrated better extraction yields than acetone and ethyl acetate (Pintać et al., 2018). The higher TPC obtained in the present study may be explained considering that sequential extraction was carried out (acidified methanol, acetone and basic hydrolysis) obtaining not only soluble phenolic compounds, but also non-extractable phenolic compounds. Basic hydrolysis releases phenolic compounds associated to macromolecules (like polysaccharides), that can be retained in the food matrix and are not quantified by simple solvent extraction, these are known as the non-extractable phenolic fraction (Domínguez-Rodríguez et al., 2017).

Total flavonoid content (TFC) in grape pomace is showed in Table 2. TFC values ranged from 53.22 to $86.47 \mathrm{mg} \mathrm{CE} / \mathrm{g}$ DM for SY and CS, respectively. Grape pomace from CA, GR, PV and ME presented values between 77.45 to $71.70 \mathrm{mg} \mathrm{CE} / \mathrm{g}$ DM with no significant differences $(p>0.05)$. As previously observed for wines, flavonoids were the main fraction of phenolic compounds fraction present in grape pomace. Previously reported TFC values from CS and ME grape pomaces, obtained using acetone and acidified methanol as solvents (Pintać et al., 2018), were lower than those reported in the present study, mainly because nonextractable phenolic compounds were not quantified.

Seeds and stems present in the grape pomace are known for their content of polymerized condensed tannins and after the maceration process, large amounts of these compounds still remain in the grape pomace (Beres et al., 2017). Results of total condensed tannin content (TCT) in grape pomace are shown in Table 2. Grape pomace from PV, presented the highest TCT (23.48 mg CE/g DM) followed by CS (20.54 mg $\mathrm{CE} / \mathrm{g} \mathrm{DM})$ and $\mathrm{ME}$ (17.01 $\mathrm{mg} \mathrm{CE} / \mathrm{g} \mathrm{DM}) . \mathrm{CA}, \mathrm{SY}, \mathrm{TE}$ and ZI presented similar TCT ranged from 10.27 to $9.54 \mathrm{mg}$ $\mathrm{CE} / \mathrm{g}$ DM. BA showed the lowest TCT value (7.23 mg CE/g $\mathrm{DM})$. TCT from skins and seeds of grape pomaces presented values of $10.65 \mathrm{mg} \mathrm{CE} / \mathrm{g} \mathrm{DM}$ and $82.49 \mathrm{mg} \mathrm{CE} / \mathrm{g} \mathrm{DM}$ for CS (skins and seeds respectively), and 13.28 and $89.63 \mathrm{mg}$ CE/g DM for ZI (skins and seeds) (Rockenbach et al., 2011). These TCT values were measured using the vanillin in methanol method and were higher than those observed in the present study. So, as in the case of wines, these differences in TCT can be explained mainly in terms of the quantification method used, vanillin in methanol method, overestimates the TCT.

Values of anthocyanin content (TAC) in grape pomace are expressed in Table 2. Results showed similar TAC for most of the grape pomaces, with values in the range of 1.63 to $1.37 \mathrm{mg} \mathrm{C} 3 \mathrm{G} / \mathrm{g} \mathrm{DM}$, except for GR and CS, which presented the lowest values ( 0.77 and $0.48 \mathrm{mg} \mathrm{C} 3 \mathrm{G} / \mathrm{g} \mathrm{DM})$. When analysing these results, two factors must be taken in account. First, these results correspond only to free anthocyanins present in extracts, polymeric anthocyanins and anthocyanins linked to other phenolic compounds such as phenolic acids or condensed tannins are no quantified by this method. And second, results correspond only to methanol and acetone extracts since anthocyanins were not detected in the basic hydrolyzed extracts, because they were degraded during the basic hydrolysis due to the basic $\mathrm{pH}$ (around 13.5) and temperature used $\left(80^{\circ} \mathrm{C}\right.$ for $\left.4 \mathrm{~h}\right)$. Anthocyanins in basic $\mathrm{pH}$ undergo a degradation process (Moldovan et al., 2012). Moreover, the degradation kinetics of anthocyanins increases as temperature increase, and use of temperatures over $70^{\circ} \mathrm{C}$ increases the degradation of anthocyanins (Moldovan et al., 2012).

\section{Phenolic profile of wine and grape pomace by HPLC- ESI-MS/MS \\ Wines}

Results from the nine wine varieties are presented in Table 3. Compounds present in samples were identified using standards, databases or literature references of previously identified compounds in wines. Results are expressed as 
TABLE 3

Phenolic profile of wines determined by HPLC MS/MS.

\begin{tabular}{|c|c|c|c|c|c|c|c|c|c|}
\hline Compound Name & BA & $\mathrm{CA}$ & $\mathrm{CS}$ & GR & $\mathrm{ME}$ & PV & SY & $\mathrm{TE}$ & ZI \\
\hline \multicolumn{10}{|l|}{ Hydroxybenzoic acids } \\
\hline$m$-Hydroxybenzoic acid & ND & ND & ND & ND & 12222 & ND & ND & ND & ND \\
\hline Gallic acid & 234013 & 206385 & 305869 & 250053 & 286730 & 389422 & 213917 & 306402 & 535664 \\
\hline Protocatechuic acid & 44175 & 43724 & 43417 & 50065 & 40110 & 32308 & 50225 & 54078 & 62219 \\
\hline Vanillic acid & ND & ND & ND & ND & 9049 & 9399 & ND & ND & ND \\
\hline \multicolumn{10}{|l|}{ Hydroxycinnamic acids } \\
\hline$p$-coumaric acid & 101229 & ND & 143886 & 160212 & 37930 & ND & 139010 & 171764 & 114544 \\
\hline$p$-coumaroyl glucoside & 49266 & 66594 & 17940 & 44804 & 46593 & 79544 & 98197 & 98811 & 70135 \\
\hline Caffeic acid & 174906 & 119651 & 240674 & 139832 & 96473 & 305734 & 195664 & 215338 & 278962 \\
\hline Caffeoyl malic acid & 110621 & 131419 & 166023 & 177929 & 38844 & 247627 & 143773 & 182262 & 107548 \\
\hline Caffeoyl tartaric acid & 175784 & 146603 & 247551 & ND & 118714 & 315212 & 222157 & 245087 & 290861 \\
\hline Dicaffeoyl quinic acid & 23878 & ND & 28515 & ND & 39179 & 28638 & ND & ND & ND \\
\hline Ferulic acid & 12121 & ND & ND & ND & ND & 13248 & 12189 & 11164 & 19643 \\
\hline Ferulic acid methyl ester & 36429 & 20124 & 57527 & 15810 & 45496 & 29887 & 29883 & 9436 & 52586 \\
\hline \multicolumn{10}{|l|}{ Phenylethanoids } \\
\hline Hydroxytyrosol & 27940 & 119080 & ND & 20891 & ND & ND & 26229 & ND & ND \\
\hline Hydroxytyrosol glucoside & 70971 & 57677 & ND & ND & ND & ND & 70108 & 48325 & ND \\
\hline \multicolumn{10}{|l|}{ Stilbenes } \\
\hline trans-Resveratrol & ND & ND & ND & ND & 14506 & 347421 & ND & ND & ND \\
\hline \multicolumn{10}{|l|}{ Flavonols } \\
\hline Quercetin & ND & ND & 10742 & ND & ND & ND & ND & ND & ND \\
\hline Isoquercetin & 197094 & 76477 & 37921 & 44097 & 40378 & 28989 & 223921 & 259985 & 76905 \\
\hline Dihydroquercetin & 19309 & ND & ND & ND & 10625 & 6701 & 10851 & ND & 39107 \\
\hline Isorhamnetin-3-O- glucoside & ND & ND & ND & ND & ND & ND & 86908 & ND & ND \\
\hline Kaempferol-3-O-glucoside & ND & ND & ND & 15745 & ND & ND & ND & 50687 & ND \\
\hline Myricetin-3-glucoside & 182493 & 134953 & 123017 & 88350 & 76549 & 159889 & 193397 & 329223 & 166984 \\
\hline Myricetin-3-glucoronide & 6274 & ND & 10497 & 13209 & ND & 11846 & ND & 14418 & 10627 \\
\hline Syringetin-3-glucoside & 46145 & 12884 & 56063 & 33578 & 36329 & 73566 & 82041 & 69399 & 43761 \\
\hline \multicolumn{10}{|l|}{ Flavan-3-ols } \\
\hline Epicatechin & 110529 & 35595 & 203422 & 51675 & 113806 & 388366 & 75709 & 131909 & 473619 \\
\hline Catechin & 88916 & 49226 & 263545 & 73564 & 128977 & ND & 67636 & 123964 & 432529 \\
\hline Epigallocatechin & 20460 & 17164 & 17578 & ND & 28823 & 19556 & ND & ND & ND \\
\hline Methyl ellagic acid glucoside & 141254 & 55293 & 86895 & 90763 & 48682 & 47404 & 103506 & 95432 & 102937 \\
\hline B-Type Procyanidin dimer 1 & 95413 & 59429 & 141571 & 92372 & ND & 225514 & ND & ND & 379221 \\
\hline B-Type Procyanidin dimer 2 & 94036 & ND & 120625 & ND & 56792 & 170708 & 56993 & 83237 & ND \\
\hline B-Type Procyanidin trimer 1 & 35556 & 17293 & 45943 & 29497 & 17573 & 68268 & 19584 & 32384 & 103295 \\
\hline B-Type Procyanidin trimer 2 & 22590 & ND & ND & 16478 & ND & ND & 10763 & ND & 83053 \\
\hline Prodelphinidin T2/T3 & ND & ND & 32176 & ND & ND & ND & ND & ND & ND \\
\hline
\end{tabular}

Results are expressed as area under the curve (AUC). BA=Barbera. $\mathrm{CA}=$ Carignan. $\mathrm{CS}=$ Cabernet Sauvignon. $\mathrm{GR}=\mathrm{Grenache} . \mathrm{ME}=\mathrm{Merlot}$. $\mathrm{PV}=$ Petit Verdot. $\mathrm{SY}=$ Syrah. $\mathrm{TE}=$ Tempranillo. $\mathrm{ZI}=$ Zinfandel. $\mathrm{ND}=$ Not detected compound. 
peak area (or area under the curve, AUC) of each identified compound. A total of 36 phenolic compounds were identified in wine samples.

Hydroxybenzoic acids found in samples were mainly gallic acid and protocatechuic acid. ZI wine presented a higher concentration of gallic acid than the other wine samples. Protocatechuic acid was present in lower concentration than gallic acid. Even though, protocatechuic acid presented a similar trend to gallic acid. Gallic acid has been reported as the main hydroxybenzoic acid present in red wines(Ivanova-Petropulos et al., 2015). In the case of hydroxycinnamic acids, caffeic acid and their derivates were predominant compared with p-coumaric acid and ferulic acid and their derivates. This is in accordance with other authors that have reported that caffeoyl tartaric acid is more abundant in red wines (Lukić et al., 2019). Differences in the hydroxybenzoic and hydroxycinnamic content in red wines, has been attributed to the pathways involved in the benzoic acid biosynthesis, that is modified by rainfall and temperature during grape maturation (Belmiro et al., 2017).

Flavonols identified by HPLC MS/MS in the wine samples were quercetin, myricetin, and their glycosylated and glucuronide derivatives. On the other hand, isorhamnetin and syringetin were found only in their glycosylated forms. Flavanol glycosides occurring naturally in grapes and during fermentation can be released as aglycones (Lukić et al., 2019). This release was observed only in CS wine were quercetin was identified. Isoquercetin was identified in all the samples and TE showed the highest content. Myricetin3-glucoside also was present in all samples in contrast with their glucuronide derivative that only was identified in some samples. Both derivatives were more abundant in TE. On the other hand, syringetin-3-glucoside was identified in all samples and, the highest abundant was found in SY. According to Lukić et al. (2019), flavonols have been proposed to differentiate wine, but still, no clear results have been observed.

Monomeric flavan-3-ols found in wine samples were mainly catechin and epicatechin. Catechin was identified in all samples, except in PV. ZI wine presented the highest catechin and epicatechin content. In contrast, epigallocatechin was identified only in 5 samples, at lesser content. ME presented the highest epigallocatechin content. Wines also presented B-type procyanidins; ZI wine presented the highest content of procyanidin B-type dimer 1. Meanwhile procyanidin B-type dimer 2, was more abundant on PV. Results showed that dimer 2 was not identified in ZI wine. Only wines from BA, CS and PV presented the two different dimers. On the other hand, B-type procyanidin trimers were identified in wines. ZI wine presented the highest content of trimers 1 and 2. CS was the only sample that presented prodelphinidin. Content of flavan-3-ols has been reported in differentiate red wines (Lukić et al., 2019). In the present study, red wines can be differentiated by the presence of epigallocatechin, prodelphindin, dimers and timers of procyanidins.

In the case of stilbenes, trans-resveratrol was only identified in ME and PV wines, and was more abundant in PV. Hydroxytyrosol was identified in samples from BA, CA, GR and SY wines. On the other hand, glycosiltaed hydrxyotyrosol was also identified in BA, CA, SY and TE wines. This compounds has been identified in grape pomace seeds (Teixeira et al., 2014), and may be extracted during the maceration process.

PCA was performed using the AUC data of phenolic profile by families of compounds (sum of AUC of all phenolic compounds from the same type of compounds), to observe differentiations between the nine wine varieties. Cumulative percentage using first and second principal components explain the $72.52 \%$ of the total variance (Figure $1 \mathrm{~A}$ ). HCA analysis shows that the nine wine varieties were differently grouped according to their phenolic profile (Figure 1B). The first cluster was formed by ZI, GR and PV characterized to have the highest abundance in monomeric and oligomeric flavan-3-ols and hydroxybenzoic acids. The second cluster formed by BA, TE SY, ME, CS and CA were characterized to have the highest abundance of flavonols, phenylethanoids and methyl ellagic acid glucoside.
A

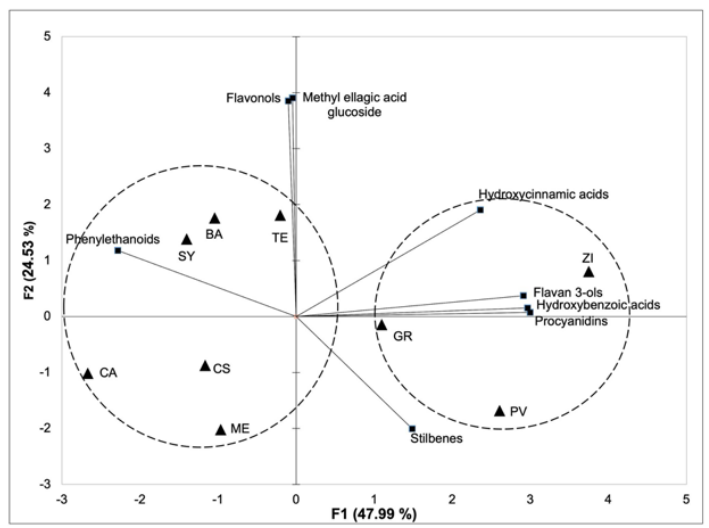

B

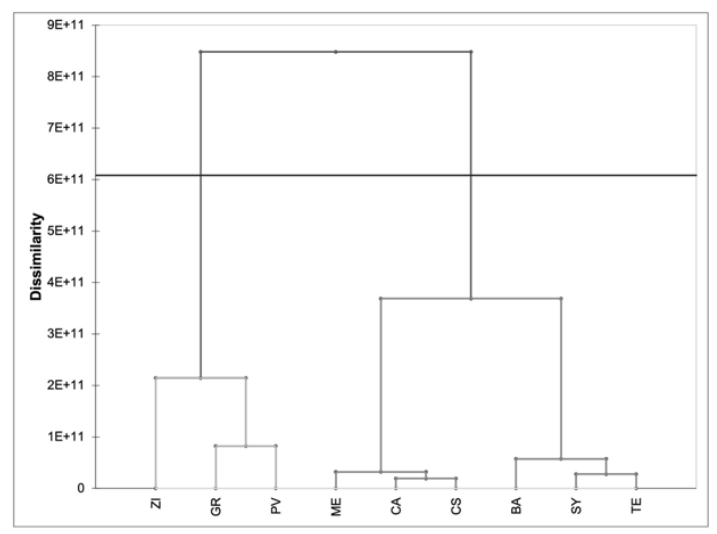

FIGURE 1

A. Biplot obtained from PCA showing the relationship between phenolic profile and the different wine samples.

B. Hierarchical cluster analysis of wine samples. 
TABLE 4

Phenolic profile of grape pomace determined by HPLC MS/MS.

\begin{tabular}{llllllllll}
\hline Compound Name & BA & CA & CS & GR & ME & PV & SY & TE & ZI \\
\hline Hydroxybenzoic acids & & & & & & & & & \\
Gallic acid & 35786 & 22010 & 47087 & 31832 & 80489 & 89992 & 21613 & 24081 & 30387 \\
Syringic acid & 13918 & 15627 & 22652 & 10182 & 30103 & 21572 & 9283 & 12976 & 18839 \\
Galloyl glucoside & ND & 8805 & 27942 & ND & 24528 & 48268 & ND & ND & ND \\
Flavonols & & & & & & & & & \\
Kaempferol & 39506 & 20225 & ND & 9004 & 8502 & ND & 8021 & 8159 & ND \\
Quercetin & 149110 & 57160 & 33803 & 40612 & 47601 & ND & 49926 & 45978 & 37660 \\
Isoquercetin & 21544 & 25651 & 12809 & 20140 & ND & 23560 & 51491 & 32498 & ND \\
Laricitin-3-O-glucoside & 6005 & ND & ND & 7693 & ND & ND & 9789 & ND & ND \\
Syringetin-3-O - glucoside & 9525 & ND & ND & 15319 & ND & 22408 & 15917 & 9647 & ND \\
Flavan-3-ols & & & & & & & & & \\
Catechin & ND & 29601 & 91220 & 28953 & 90735 & 253804 & 10109 & 33187 & 21714 \\
Epicatechin & ND & 31635 & 85072 & 26483 & 106143 & 201268 & 18775 & 40169 & 25961 \\
Catechin gallate & ND & 7638 & 15059 & ND & 23607 & 42071 & ND & 11964 & 9755 \\
Methyl ellagic acid glucoside & 55486 & 40135 & 19048 & 29594 & ND & ND & 27068 & ND & 23617 \\
B-Type Procyanidin dimer 1 & ND & 23974 & 33480 & 16735 & 19840 & 35956 & ND & ND & ND \\
B-Type Procyanidin dimer 2 & ND & 31146 & 40424 & 31703 & 38919 & 96397 & ND & ND & ND \\
B-Type Procyanidin trimer 1 & ND & ND & 11934 & ND & ND & 20076 & ND & ND & ND \\
B-Type Procyanidin trimer 2 & ND & ND & 17437 & ND & ND & 40591 & ND & ND & ND \\
\hline
\end{tabular}

Results are expressed as area under the curve (AUC). $\mathrm{BA}=$ Barbera. $\mathrm{CA}=$ Carignan. $\mathrm{CS}=$ Cabernet Sauvignon. $\mathrm{GR}=\mathrm{Grenache}$. ME=Merlot. $\mathrm{PV}=$ Petit Verdot. $\mathrm{SY}=$ Syrah. $\mathrm{TE}=$ Tempranillo. $\mathrm{ZI}=$ Zinfandel. ND=Not detected compound.

\section{Pomace}

Phenolic profile of grape pomaces is reported in Table 4. Seventeen phenolic compounds were identified. Gallic and syringic acid were identified in all grape pomace samples. PV showed the highest content of gallic and its derivative galloyl glucoside. Meanwhile ME presented the highest abundant of syringic acid. As observed in wines, gallic acid was more abundant in samples compared to syringic acid.

Kaempferol and quercetin, were identified only in their aglycone form. The highest abundance of kaempferol was found in BA. Quercetin was identified in almost all the grape pomaces except in $\mathrm{PV}$, and the highest abundance was also found in BA. Three glycosylated flavanols were identified in grape pomace samples, laricitin, syringetin and isoquercetin. SY presented the highest abundance of laricitrin and isoquerecetin, while syringetin was more abundant in PV.

Monomeric flavan-3-ols identified in grape pomace samples were mainly catechin and epicatechin. In contrast to wine, epigallocatechin was not identified in any sample. Nevertheless, catechin gallate was observed in grape pomace samples. Grape pomace samples presented 2 B-type procyanidins dimers. Dimers were identified only in CA, CS, GR, ME and PV. PV presented the highest abundance in both dimers. B-type procyanidins trimers were identified only in CS and PV. As observed in monomeric flavan-3-ols, PV also presented the highest abundance in oligomeric flavan-3-ols. These results may indicate that PV grape pomace content a large quantity of flavanols mainly in seeds and were not transferred into wine during maceration process.

Results from PCA showed that cumulative percentage using first and second principal components explained the $77.43 \%$ of the total variance (Figure $1 \mathrm{~A}$ ). HCA analysis that 3 cluster were formed (Figure 2B). As can be observed, $\mathrm{PV}$ was alone and was associated with monomeric and polymeric flavan-3-ols. A second cluster was formed by ME and GR that were characterized by their content in gallic and syringic acid. ME is more influenced by their syringic acid content and GR by its gallic acid content. Samples from CS, TE, CS, SY, BA and ZI were grouped together due to their quercetin, kaempferol, methyl ellagic acid content.

\section{Antiplatelet activity of wine and grape pomace}

In the present study an in vitro assay was performed to evaluate the anti-aggregation effect of samples from the nine red wines varieties and their grape pomaces. Experiments for the antiplatelet effect of wines, were performed with dealcoholized samples. To avoid interferences from alcohol in the results, wine samples used in the present study were dealcoholized and lyophilized, in order to evaluate the specific effect of phenolic compounds present in samples 
A

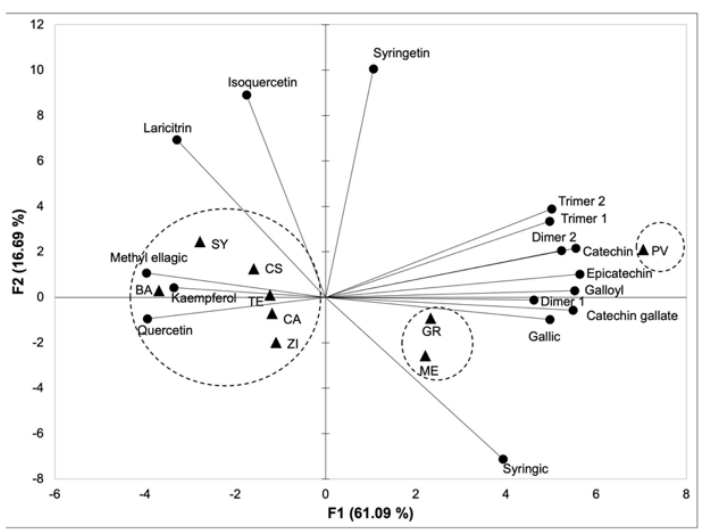

$B$

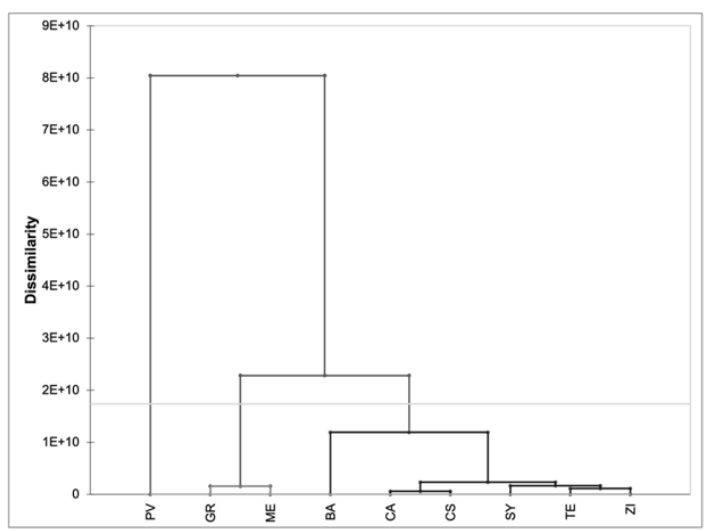

FIGURE 2

Biplot obtained from PCA showing the relationship between phenolic profile from and the different grape pomace samples.

B. Hierarchical cluster analysis of grape pomace samples.

A

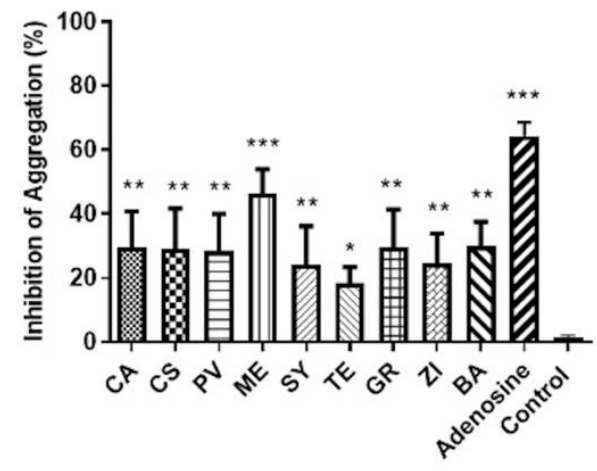

B

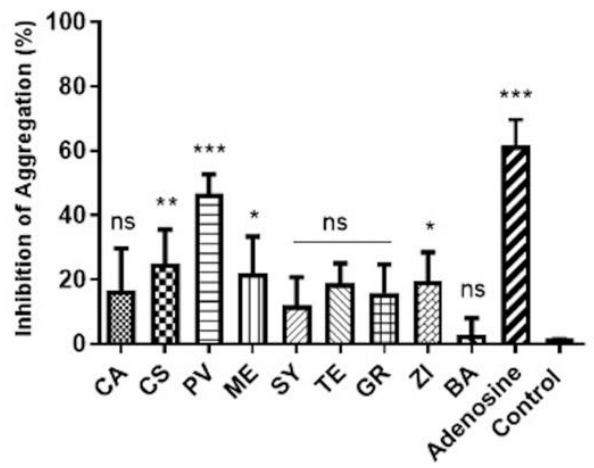

FIGURE 3

Antiplatelet effect of wines. A. Effect against ADP $(4 \mu \mathrm{M})$. B. Effect against TRAP-6 $(10 \mu \mathrm{M})$. The PRP was incubated with PBS or wines $(1 \mathrm{mg} / \mathrm{mL})$ for 3 minutes at $37^{\circ} \mathrm{C}$ and then stimulated with ADP or TRAP- 6 to start platelet aggregation for 6 minutes. The graphs represent the mean \pm standard deviation of $n=6$ experiments. The $\mathrm{p}$ values were calculated using ANOVA and Tukey's post-hoc test, ${ }^{*} \mathrm{p}<0.05,{ }^{*} \mathrm{p}<0.01$ and $* * * \mathrm{p}<0.001$ denotes a statistically significant difference compared to the negative control (absence of wines), ns: not statistically significant.

against platelet aggregation.

The effect of wine against the ADP-induced platelet aggregation is shown in Fig. 3A. Results are expressed as inhibition percentage of platelet aggregation. TE presented the lowest effect (18.4\%), while ME phenolic compounds presented the highest platelet aggregation inhibition (46.3\%). When TRAP-6 was used to induce platelet aggregation (Fig. $3 \mathrm{~B}$ ), a different effect of wines on platelet aggregation was observed. PV wine presented the highest platelet aggregation inhibitory effect (46.7\%), followed by CS $(25.0 \%)$, ME and ZI (21.8\% and $19.7 \%$, respectively). All other varieties presented non-significant effects. The antiplatelet activity of grape pomace against ADP and TRAP is shown on
Fig. 4A and 4B, respectively. PV grape pomace was the only sample that showed significant platelet aggregation, at the assayed conditions, with $67.1 \%$ inhibition of ADPinduced aggregation and 53.2\% inhibition of TRAP-induced aggregation.

Agonists used in the present study activate different signalling pathways. ADP is considered a weak agonist (Cattaneo, 2019), and is involved in the amplification of the signalling for platelet recruiting (Broos et al., 2012). ADP activates platelet aggregation by direct binding to different receptors like P2Y1 and, P2Y12 belonging to the family of transmembrane ADP receptors, and $\mathrm{P} 2 \mathrm{X}_{1}$ an ATPC receptor (Clemetson \& Clemetson 2019). In the other hand, TRAP- 
A

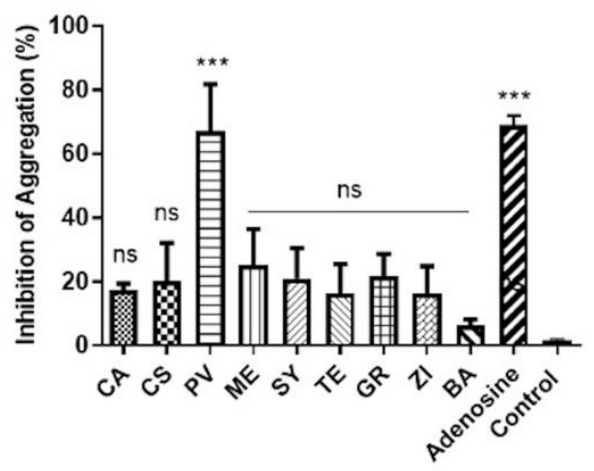

B

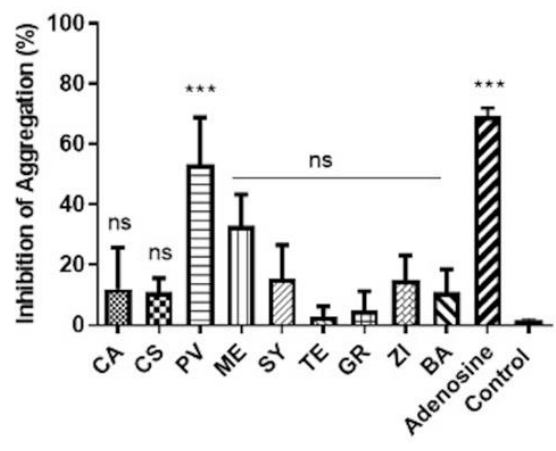

FIGURE 4

Antiplatelet effect of grape pomace. A. Effect against ADP $(4 \mu \mathrm{M})$. B. Effect against TRAP-6 $(10 \mu \mathrm{M})$. The PRP was incubated with PBS or grape pomace $(1 \mathrm{mg} / \mathrm{mL})$ for 3 minutes at $37{ }^{\circ} \mathrm{C}$ and then stimulated with ADP or TRAP-6 to start platelet aggregation for 6 minutes. The graphs represent the mean \pm standard deviation of $n=6$ experiments. The $p$ values were calculated using ANOVA and Tukey's post-hoc test, $* * * \mathrm{p}<0.001$ denotes a statistically significant difference compared to the negative control (absence of grape pomace), ns: not statistically significant.

6 activates platelet aggregation by binding to a thrombin receptor. Thrombin is a more potent platelet activator compared to ADP (Gremmel et al., 2014). Thrombin receptors, known as protease activation receptors (PAR1), are representative G-coupled transmembrane receptors involved in platelet aggregation (Gremmel et al. 2014, Clemetson \& Clemetson 2019). TRAP-6 activates platelet aggregation through 4 receptors PAR1, PAR4 and glycoprotein Ib $\alpha$ and glycoprotein V (GPV). Results showed a different behaviour in wines, the ME wine having the highest antiplatelet activity by ADP and PV by TRAP-6. These results may indicate that phenolic compounds present in both samples acts differently in the mechanism of platelet aggregation.

According to PCA performed, ME and PV wines were grouped differently by their phenolic profile. This could explain the different behaviour observed against each agonist. ME wine was characterized to have $m$-hydroxybenzoic acid and the highest abundance of epigallocatechin (Table 3). In the other hand, PV wine was characterized with the highest abundance of caffeic acid and their derivatives, transresveratrol and B-type procyanidin dimer 2, also was the only sample were catechin was not identified (Table 3 ). In a previous study, flavan-3-ols from dark chocolate were associated with reduction of platelet aggregation induced by ADP and TRAP-6 (Rull et al., 2015); this may explain the effect observed in PV wine that presented the highest abundance of epigallocatechin in contrast with the other wine samples used in the present study. Nevertheless, transresveratrol presence in both samples cannot be discarded. Phenolic profile results showed ME, and PV were the only samples with trans-resveratrol, showing PV higher content compared to ME. Resveratrol is one of the phenolic compounds present in wine associated with cardioprotective effect in red wines. Previous studies have evaluated the effect or resveratrol against platelet aggregation (Gresele et al., 2008; Bonechi et al., 2017). According to Gresele et al. (2008), one of the action of resveratrol is reducing reactive oxygen species (ROS) and increases nitric oxide
(NO) production in platelets. In other study, resveratrol also showed to inhibit platelet aggregation induced by ADP and thrombin and observe that resveratrol can block the synthesis of thromboxane A2 (TxA2) (Pace-Asciak et al., 1995). TxA2 is one of the metabolites produced during platelet aggregation, implicated in the amplification of platelet aggregation signalling (Broos et al., 2012). TxA2 is mainly produced by action of thrombin and may explain the better effect observed of PV against TRAP-6. Other studies have observed that resveratrol is not the only responsible to inhibit platelet aggregation and a mixture of phenolic compounds can be acting to observe the cardioprotective effect (Gresele et al., 2008). This may suggest that in ME wine, even if resveratrol is present at a lower concentration, it can be acting along with $m$-hydroxybenzoic acid and epigallocatechin.

In contrast to wines, grape pomace presented lower platelet aggregation inhibitory values. The only sample with significant difference $(\mathrm{p}<0.05)$ was $\mathrm{PV}$ grape pomace. Interestingly, according to PCA, PV was alone according to its phenolic profile. PV was characterized to contain the highest amount of flavan-3-ols, monomeric and oligomeric, compared to the rest of the samples. In a previous study, flavan-3-ols monomeric and dimers showed to inhibit platelet aggregation induced by ADP (Murphy et al., 2003), even though, more studies are needed to observe this phenomenon. Other authors observed that monomeric and oligomeric flavan-3-ols had a better effect against platelet aggregation compared to phenolic acids and resveratrol (Russo et al., 2001), they attributed to a synergetic effect of monomeric and oligomeric flavan-3-ols and observed an increase in cAMP levels, when ADP agonist is coupled to P2Y12 receptor, leading to inhibition of adenyl cyclase and prevent the arise of cAMP. These may indicate that flavan3-ols monomeric and oligomeric present in PV could be altering this platelet aggregation mechanism. Nevertheless, more studies are needed to confirm this mechanism of phenolic compounds from PV grape pomace. In a study conducted by de Lange et al. (2007), a grape extract was 
probed against platelet aggregation induced by TRAP and ADP, they attributed these effect by calcium $\left(\mathrm{Ca}^{2+}\right)$ mobilization and inositol triphosphate inhibition, both play a key role in platelet aggregation. Nevertheless, no specific phenolic compound was related to this effect, but such extract contained catechin, epicatechin, caffeic and gallic acid. Similar phenolic profile than identified in PV. This could suggest that probably phenolic compounds present in PV can interact with such platelet aggregation mechanism, but such a hypothesis has yet to be tested.

\section{CONCLUSIONS}

Results from the present study showed that ZI wine and CS grape pomace, were the samples with the highest phenolic content by Folin-Ciocalteu method. Spectrophotometric results showed that samples from wines and grape pomace presented mainly flavonoids. PCA grouped wines according to their phenolic profile, observing that ZI, PV and GRE wines were grouped due to its hydroxybenzoic acid and flavan-3ols content. On the other hand, PV grape pomace was alone due to its monomeric and polymeric flavan-3-ols content. Regarding antiplatelet activity, ME and PV wines presented the highest inhibition. Meanwhile, PV grape pomace was the only sample that showed platelet aggregation inhibitory effect against ADP and TRAP agonists. Limitations from this study are the number of samples used and use of statistics to differentiate monovarietal red wines. Also, the phenolic profile determined from samples is not sufficient to provide exact information of possible phenolic compounds with antiaggregant effects. Nevertheless, more studies should be done to evaluate the behavior of pure phenolic compounds at similar content than those observed in wine and grape pomace samples against platelet aggregation, also to determine the possible mechanism by which such phenolic compounds can interfere against platelet aggregation, Finally, studies to evaluate possible synergic, additive or agonistic effects of phenolics compounds found in wines and grape pomace samples against platelet aggregation should also be done.

\section{LITERATURE CITED}

Balea, S.S., Pârvu, A.E., Pop, N., Zamora, F. M. \& Pârvu, M., 2018 Polyphenolic compounds, antioxidant, and cardioprotective effects of pomace extracts from Fetească neagră cultivar. Oxid. Med. Cell. Longev. 2018, 1-11.

Belmiro, T.M.C., Pereira, C.F. \& Paim, A.P.S., 2017. Red wines from South America: Content of phenolic compounds and chemometric distinction by origin. Microchem. J. 133, 114-120.

Beres, C., Costa, G.N.S., Cabezudo, I., da Silva-James, N.K., Teles, A.S.C.., Cruz, A.P.G., Mellinger-Silva, C., Tonon, R.V., Cabral, L.M.C, \& Freitas, S.P., 2017. Towards integral utilization of grape pomace from winemaking process: A review. Waste Manag. 68, 581-594.

Bonechi, C., Lamponi, S., Donati, A., Tamasi, G., Consumi, M., Leone, G., Rossi, C. \& Magnani, A., 2017. Effect of resveratrol on platelet aggregation by fibrinogen protection. Biophys. Chem. 222, 41-48.

Born, G.V.R. \& Cross, M.J., 1963. The aggregation of blood platelets. J. Physiol. 1963, 178-195.

Broos, K., De Meyer, Feys, H.B., Vanhoorelbeke, K. \& Deckmyn, H., 2012. Blood platelet biochemistry. Thromb. Res. 129(3), 245-249.
Burin, V.M., Freitas Costa, L.L., Rosier, J.P. \& Bordignon-Luiz, M.T., 2011. Cabernet Sauvignon wines from two different clones, characterization and evolution during bottle ageing. LWT - Food Sci. Technol. 44(9), 1931-1938.

Casassa, L.F. \& Harbertson, J.F., 2014. Extraction, evolution, and sensory impact of phenolic compounds during red wine maceration. Annu. Rev. Food Sci. Technol. 5(1), 83-109.

Cattaneo, M., 2019. The platelet P2 receptors In:Michelson, A.D. (ed). Platelets (4th ed). Elsevier Inc., London, UK. pp. 261-281.

Cheng, A., Yan, H., Han, C., Chen, X., Wang, W., Xie C., Qu, J., Gong, Z. $\&$ Shi, X., 2014. Acid and alkaline hydrolysis extraction of non-extractable polyphenols in blueberries: Optimisation by response surface methodology. Czech J. Food Sci. 32(3), 218-225.

Clemetson, K.J. \& Clemetson, J.M., 2019. Platelet receptors In: Michelson, A.D. (ed). Platelets (4th ed). Elsevier Inc., London, UK. pp. 169-192.

Coletta, A., Berto, S., Crupi, P., Cravero, M.C., Tamborra, P., Antonacci, D., Daniele P.G. \& Prenesti, E., 2014. Effect of viticulture practices on concentration of polyphenolic compounds and total antioxidant capacity of Southern Italy red wines. Food Chem. 152, 467-474.

Denny, C., Lazarini, J.G., Franchin, M., Melo, P.S., Pereira, G.E., Massarioli, A.P., Moreno, I.A.M., Paschoal, J.A.R., Alencar, S.M. \& Rosalen, P.L., 2014. Bioprospection of Petit Verdot grape pomace as a source of antiinflammatory compounds. J. Funct. Foods 8(1), 292-300.

Domínguez-Rodríguez, G., Marina, M.L. \& Plaza, P., 2017. Strategies for the extraction and analysis of non-extractable polyphenols from plants. J. Chromatogr. A 1514, 1-15.

Faggio, C., Sureda, A., Morabito, S., Sanches-Silva, A., Mocan, A., Nabavi, S.F. \& Nabavi, S.M., 2017. Flavonoids and platelet aggregation: A brief review. Eur. J. Pharmacol. 807, 91-101.

Figueiredo-González, M., Martínez-Carballo, E., Cancho-Grande, B., Santiago, J.L., Martínez, M.C. \& Simal-Gándara, J., 2012. Pattern recognition of three Vitis vinifera L. red grapes varieties based on anthocyanin and flavonol profiles, with correlations between their biosynthesis pathways. Food Chem. 130(1), 9-19.

Font, I., Gudiño, P. \& Sánchez, A., 2010. La industria vinícola mexicana y las políticas agroindustriales: panorama general. Redpol. 2, 1-30.

Fuentes, M., Sepúlveda, C., Alarcón, M., Palomo, I. \& Fuentes, E., 2018. Buddleja globosa (matico) prevents collagen-induced platelet activation by decreasing phospholipase $\mathrm{C}$-gamma 2 and protein kinase $\mathrm{C}$ phosphorylation signaling. J. Tradit. Complement. Med. 8(1), 66-71.

Ghanem, C., Taillandier, P., Rizk, M., Nehme, N., Souchard, J.P. \& El Rayess, Y., 2017. Analysis of the impact of fining agents types, oenological tannins and mannoproteins and their concentrations on the phenolic composition of red wine. LWT - Food Sci. Technol. 83, 101-109.

Giuliana, M., Ciancarelli, T., Di Massimo, C., De Amicis, D., Ciancarelli, I. \& Carolei, A., 2011. Moderate consumption of red wine and human platelet responsiveness. Thromb. Res. 128 (2), 124-129.

Goula, A.M., Thymiatis, K. \& Kaderides, K., 2016. Valorization of grape pomace: Drying behavior and ultrasound extraction of phenolics. Food Bioprod. Process. 100, 132-144.

Granato, D., Santos, J.S., Maciel, L.G. \& Nunes, D.S., 2016. Chemical perspective and criticism on selected analytical methods used to estimate the total content of phenolic compounds in food matrices, Trends Analyt. Chem. 80, 266-279.

Gremmel, T., Xhelili, E., Steiner, S., Koppensteiner, R., Kopp, C.W. \& Panzer, S., 2014. Response to antiplatelet therapy and platelet reactivity to thrombin receptor activating peptide- 6 in cardiovascular interventions: Differences between peripheral and coronary angioplasty. Atherosclerosis 232(1), 119-124. 
Gresele, P., Pignatelli, P., Guglielmini, G., Carnevale, R., Mezzasoma, A.M., Ghiselli, A., Momi, S. \& Violi, F., 2008. Resveratrol, at concentrations attainable with moderate wine consumption, stimulates human platelet nitric oxide production. J. Nutr. 138(9), 1602-1608.

Ivanova-Petropulos, V., Hermosín-Gutiérrez, I., Boros, B., Stefova, M., Stafilov, T., Vojnoski, B., Dörnyei, Á \& Kilár, F., 2015. Phenolic compounds and antioxidant activity of Macedonian red wines. J. Food Compos. Anal. $41,1-14$

Jiang, B. \& Zhang, W.Z., 2012. Comparison on phenolic compounds and antioxidant properties of Cabernet Sauvignon and Merlot wines from four wine grape-growing regions in China. Molecules. 17(8), 8804-8821.

Jin, Z.M., He, J.J., Bi, H.Q., Cui, X.Y. \& Duan, C.Q., 2009. Phenolic compound profiles in berry skins from nine red wine grape cultivars in Northwest China. Molecules 14(12), 4922-4935.

Jordão, A.M. \& Ricardo-da-Silva, J.M., 2018. Evolution of proanthocyanidins during grape maturation, winemaking, and aging process of red wines In: Morata, A. (ed). Red wine technology (1st ed). Academic Press, London, UK. pp. 177-193.

de Lange, D.W., van Golde, P.H., Scholman, W.L.G., Kraaijenhagen, R.J., Akkerman, J.W.N. \& van de Wiel, A., 2003. Red wine and red wine polyphenolic compounds but not alcohol inhibit ADP-induced platelet aggregation. Eur. J. Intern. Med. 14(6), 361-366.

de Lange, D.W., Verhoef, S., Gorter, G., Kraaijenhagen, R.J., van de Wiel, A. \& Akkerman, J.W., 2007. Polyphenolic grape extract inhibits platelet activation through PECAM-1: An explanation for the French paradox. Alcohol. Clin. Exp. Res. 31(8), 1308-1314.

Lee, J., Durst, R.W. \& Wrolstad, E., 2005. Determination of total monomeric anthocyanin pigment content of fruit juices, beverages, natural colorants, and wines by the $\mathrm{pH}$ differential method: Collaborative study. J. AOAC Int. 88(5), 1269-1278.

Lingua, M.S., Fabani, M.P., Wunderlin, D.A. \& Baroni, M.V., 2016. In vivo antioxidant activity of grape, pomace and wine from three red varieties grown in Argentina: Its relationship to phenolic profile. J. Funct. Foods 20, $332-345$.

Lingua, M.S., Theumer, M.G., Kruzynski, P., Wunderlin, D.A. \& Baroni, M.V., 2019. Bioaccessibility of polyphenols and antioxidant properties of the white grape by simulated digestion and Caco- 2 cell assays: Comparative study with its winemaking product. Food Res. Int. 122, 496-505.

Lukić, I., Radeka, S., Budić-Leto, I., Bubola, M. \& Vrhovsek, U., 2019. Targeted UPLC-QqQ-MS/MS profiling of phenolic compounds for differentiation of monovarietal wines and corroboration of particular varietal typicity concepts. Food Chem. 300, 1-11.

Lutz, M., Fuentes, E., Ávila, F., Alarcón, M. \& Palomo, I., 2019. Roles of phenolic compounds in the reduction of risk factors of cardiovascular diseases. Molecules 24(2), 1-16.

Mazza, G., Fukumoto, L., Delaquis, P., Girard, B. \& Ewert, B., 1999 Anthocyanins, phenolics, and color of Cabernet Franc, Merlot, and Pinot Noir wines from British Columbia. J. Agric. Food Chem. 47(10), 40094017.

Moldovan, B., David, L., Chisbora, C. \& Cimpoiu, C., 2012. Degradation kinetics of anthocyanins from european cranberrybush (Viburnum opulus L.) fruit extracts. Effects of temperature, $\mathrm{pH}$ and storage solvent. Molecules 17(10), 11655-11666.

Muñoz-Bernal, Ó.A., Torres-Aguirre, G.A., Núñez-Gastélum, J.A., de la Rosa, L.A., Rodrigo-García, J., Ayala-Zavala, J.F. \& Alvarez-Parrilla, E., 2017. Nuevo acercamiento a la interacción del reactivo de Folin-Ciocalteu con azúcares durante la cuantificación de polifenoles totales. TIP Rev. Espec. en Ciencias Químico-Biológicas. 20(2), 28-33.
Muñoz-Bernal, Ó.A., Coria-Oliveros, A.J., Vazquez-Flores, A.A., de la Rosa, L.A., Núñez-Gastélum, J.A., Rodrigo-García, J., Ayala-Zavala, J.F. \& Alvarez-Parrilla, E., 2020. Evolution of phenolic content, antioxidant capacity and phenolic profile during cold pre-fermentative maceration and subsequent fermentation of Cabernet Sauvignon red wine. South African J. Enol. Vitic. 41, 1, 72-82.

Muñoz-Bernal, Ó.A., Coria-Oliveros, A.J., de la Rosa, L.A., RodrigoGarcía, J., Martínez-Ruiz, N.R., Sáyago-Ayerdí, S.G \& Alvarez-Parrilla, E., 2021. Cardioprotective effect of red wine and grape pomace. Food Res. Int $140,1-17$.

Murphy, K.J., Chronopoulos, A.K., Singh, I., Francis, M.A., Moriarty, H., Pike, M.J., Turner, A.H., Mann, N.J. \& Sinclair, A.J., 2003. Dietary flavanols and procyanidin oligomers from cocoa (Theobroma cacao) inhibit platelet function. Am. J. Clin. Nutr. 77(6), 1466-1473.

Oliveira, D.A., Salvador, A.A., Smânia, A.J., Smânia, E.F.A., Maraschin, M. \& Ferreira, S.R.S., 2013. Antimicrobial activity and composition profile of grape (Vitis vinifera) pomace extracts obtained by supercritical fluids. J. Biotechnol. 164(3), 423-432.

Ortega-Regules, A., Romero-Cascales, I., López-Roca, J.M., Ros-García, J.M. \& Gómez-Plaza, E., 2006. Anthocyanin fingerprint of grapes: environmental and genetic variations. J. Sci. Food Agric. 86(10), 1460 1467

Pace-Asciak, C.R., Hahn, S., Diamandis, E.P., Soleas, G. \& Goldberg, D.M., 1995. The red wine phenolics trans-resveratrol and quercetin block human platelet aggregation and eicosanoid synthesis: Implications for protection against coronary heart disease. Clin. Chim. Acta 235(2), 207-219.

Panceri, C.P., De Gois, J.S., Borges, D.L.G. \& Bordignon.Luiz, M.T., 2015. Effect of grape dehydration under controlled conditions on chemical composition and sensory characteristics of Cabernet Sauvignon and Merlot wines. LWT - Food Sci. Technol. 63(1), 228-235.

Payne, M.J., Hurst, W.J., Stuart, D.A., Ou, B., Fan, E., Ji, H. \& Kou, Y., 2010. Determination of total procyanidins in selected chocolate and confectionery products using DMAC. J. AOAC Int. 93(1), 89-96.

Pintać, D., Majkić, T., Torović, L., Orčić, D., Beara, I., Simin, N., MimicaDukić, N. \& Lesjak, M., 2018. Solvent selection for efficient extraction of bioactive compounds from grape pomace. Ind. Crops Prod. 111, 379-390.

Preys, S., Mazerolles, G., Courcoux, P., Samson, A., Fischer, U., Hanafi, M., Bertrand, D. \& Cheynier, V., 2006. Relationship between polyphenolic composition and some sensory properties in red wines using multiway analyses. Anal. Chim. Acta 563, 126-136.

Rockenbach, I.I., Gonzaga, L.V., Rizelio, V.M., Gonçalves, A.E. S. S., Genovese, M.I. \& Fett, R., 2011. Phenolic compounds and antioxidant activity of seed and skin extracts of red grape (Vitis vinifera and Vitis labrusca) pomace from Brazilian winemaking. Food Res. Int. 44(4), 897901 .

Rull, G., Mohd-Zain, Z.N., Shiel, J., Lundberg, M.H., Collier, D.J., Johnston, A., Warner, T. D. \& Corder, R., 2015. Effects of high flavano dark chocolate on cardiovascular function and platelet aggregation. Vascul. Pharmacol. 71, 70-78.

Russo, P., Tedesco, I., Russo, M., Russo, G.L., Venezia, A. \& Cicala, C., 2001. Effects of de-alcoholated red wine and its phenolic fractions on platelet aggregation. Nutr. Metab. Cardiovasc. Dis. 11(1), 25-29.

Schofield, P., Mbugua, D.M. \& Pell, A.N., 2001. Analysis of condensed tannins: a review. Anim. Feed Sci. Technol. 9, 21-40.

Sepúlveda, C., Hernández, B., Burgos, C.F., Fuentes, E., Palomo, I. \& Alarcón, M., 2019. The cAMP/PKA pathway inhibits Beta-amyloid peptide release from human platelets. Neuroscience. 397, 159-171.

Teixeira, A., Baenas, N., Dominguez-Perles, R., Barros, A., Rosa, E., Moreno, D.A. \& Garcia-Viguera, C., 2014. Natural bioactive compounds from winery by-products as health promoters: A review. Int. J. Mol. Sci. 15(9), 15638-15678. 
Torres-Aguirre, G., Muñoz-Bernal, Ó., Alvarez-Parrila E., NúñezGastelum, J.A., Wall-Medrano, A., Sáyago-Ayerdi, S.G. \& de la Rosa, L.A., 2018. Optimization of the extraction and identification of polyphenolic compounds in aniseed (Pimpinella anisum), clove (Syzygium aromaticum) and coriander (Coriandrum sativum) through HPLC coupled to mass spectrometry. TIP Rev. Espec. en Ciencias Químico-Biológicas. 21(2), 103-115.

Tournour, H.H., Segundo, M.A., Magalhães, L.M., Barreiros, L., Queiroz, J. \& Cunha, L.M., 2015. Valorization of grape pomace: Extraction of bioactive phenolics with antioxidant properties. Ind. Crops Prod. 74, 397-406.
Versari, A., du Toit, W. \& Parpinello, G.P., 2013. Oenological tannins: a review. Aust. J. Grape Wine Res. 19(1), 1-10.

Wang, S., Amigo-Benavent, M., Mateos, R., Bravo, L. \& Sarriá, B., 2017. Effects of in vitro digestion and storage on the phenolic content and antioxidant capacity of a red grape pomace. Int. J. Food Sci. Nutr. 68(2), $188-200$.

Wang, Z., Huang, Y., Zou, J., Cao, K., Xu, Y. \& Wu, J.M., 2002. Effect of red wine and wine polyphenol resveratrol on platelet aggregation in vivo and in vitro. Int. J. Mol. Med. 9, 77-79. 